\title{
FISCALIDAD EN EL ESTADO SOBERANO DEL TOLIMA, 1863-1885
}

Joaquín Pinto*

Salomón Kalmanovitz**

Z1 desarrollo de la historiografía fiscal es incipiente en Colomy Cartagena (Meisel, 2012), y trabajos que miden agregados económicos sin considerar las series anuales distribuidas por cajas, con cifras quinquenales agrupadas por macro regiones (Meisel, 2011), y apenas se han hecho estudios sobre el periodo 1800-1863, salvo el de Junguito (2010), que hace un seguimiento completo de las cifras nacionales y de la política fiscal, y el de Pinto (2011), quien hace en detalle ese mismo trabajo para los departamento de la República de Colombia entre 1819 y 1830 . E1 periodo federal comprendido entre 1863 y 1885 ha sido tratado de manera general por Kalmanovitz y López (2010), quienes hacen un análisis global de la situación de los Estados soberanos, ampliado al caso de Panamá hasta su separación de Colombia (Kalmanovitz, 2012). También existen estudios sobre Santander entre 1865 y 1879 (Pico, 2011), Bolívar (Wong, 1999), Cundinamarca (López y Castillo, 2012) y Tolima (Clavijo, 1993).

Esta lista muestra que hay un amplio campo de investigación en el que las monografías regionales son un insumo necesario para proporcionar una visión más amplia. Por ello exploramos la fiscalidad del Estado Soberano del Tolima entre 1863 y 1885, aportando información cuantitativa y cualitativa adicional a la de otros trabajos.

* Profesor de la Universidad del Tolima, Bogotá, Colombia [josejoaqo@ yahoo.com].

** Profesor emérito de la Universidad Jorge Tadeo Lozano, Bogotá, Colombia, [salomon.kalmanovitz@utadeo.edu.co]. Fecha de recepción: 26-08-2016, fecha de modificación: 03-02-2017, fecha de aceptación: 27-04-2017. Sugerencia de citación: Pinto, J y S. Kalmanovitz, S. "Fiscalidad en el Estado Soberano del Tolima, 1863-1885", Revista de Economía Institucional 19, 36, 2017, pp. 175-201. DoI: https://doi.org/10.18601/01245996.v19n36.07. 
El artículo analiza la política fiscal y sus resultados cuantitativos como aspectos dependientes del contexto político y económico de la región. En la primera parte se describen en forma general los antecedentes económicos entre el periodo colonial tardío y mediados del siglo xIx; luego se aborda el desarrollo de las actividades productivas y de las instituciones de gobierno entre 1863 y 1886; después se examina la política fiscal adoptada por el Estado y se analizan las series de ingresos y egresos fiscales. Por último, se interpretan con base en el devenir político y económico regional.

\section{EL ALTO MAGDALENA EN EL PERIODO 1780-1863. ALGUNAS CARACTERÍSTICAS ECONÓMICAS}

En las postrimerías del periodo colonial, el territorio que se convertiría en el Estado Soberano del Tolima estaba conformado por las provincias de Neiva, con el $64 \%$ de la población, y Mariquita, con el 36\%, la cual según el censo de 1778 era en su mayoría mestiza y libre, con una alta proporción de blancos. Los indígenas eran el tercer grupo poblacional en magnitud, mientras que los esclavos solo representaban el $10 \%$ de la población de esas dos provincias. Los focos de concentración urbana eran Ambalema, Ibagué, Mariquita y Neiva (Tovar, 1994).

La región no fue ajena a las reformas borbónicas, un conjunto de medidas que pretendían mejorar la administración en los territorios de las Indias, a fin de aumentar los ingresos fiscales para apoyar el aparato de defensa imperial y conservar el monopolio comercial que reportaría beneficios económicos a la metrópoli. Esas medidas se empezaron a adoptar en la Nueva Granada en 1717 con el proyecto de instauración del Virreinato, que fracasaría y solo se establecería en 1739. Su mayor impulso ocurrió en 1778 con la llegada del Visitador Francisco Gutiérrez de Piñeres, en la época del Virrey Manuel Antonio Flórez, cuando se crearon los monopolios de aguardiente y tabaco por administración directa, se reorganizó el cobro de las alcabalas y se estableció la junta superior de hacienda, medidas que el Virrey Antonio Caballero y Góngora aplicaría con todo rigor.

Esas reformas tuvieron gran impacto en la región, pues prefigurarían las características de su actividad económica hasta bien entrado el siglo xIx. Honda se consolidó como punto comercial estratégico entre la Costa Atlántica y el interior, y hubo grandes avances en la producción de tabaco. La creación del distrito y la factoría de Ambalema, cuya administración se ubicó en Honda y debía suplir la demanda de Antioquia, Santa Marta, Riohacha, Mompox, Neiva, 
Tocaima, Guaduas y Mariquita (González, 2005), aseguró a la Corona una fuente de recursos, amplió el mercado para la producción regional e indujo un crecimiento de la actividad tabacalera. El puerto de Honda se vio favorecido por la apertura del libre comercio desde 1778 y, sobre todo, por los permisos otorgados a Cartagena para comerciar con colonias extranjeras y neutrales en la década de 1780 , que al ser revocados provocarían un descenso del recaudo de impuestos comerciales en ese puerto.

Esas tendencias se observan cuando se analizan las series de cargo de la Caja Real de Honda entre 1780 y 1809, donde el 48\% de su ingreso provenía de monopolios y el $24 \%$ de gravámenes comerciales. La gráfica 1 , que muestra el comportamiento de esos dos rubros, indica que el monopolio se mantiene estable entre 1780 y comienzos de la década de 1790, cuando su aporte decae para recuperarse en el quinquenio 1795-1800: luego inicia un descenso lento pero sostenido. Los ingresos del comercio se mantuvieron estables hasta la primera década del siglo XIX, cuando empezaron a caer.

Gráfica 1

Cargo por monopolios y comercio de la Caja Real de Honda, 1780-1809 (Pesos plata)

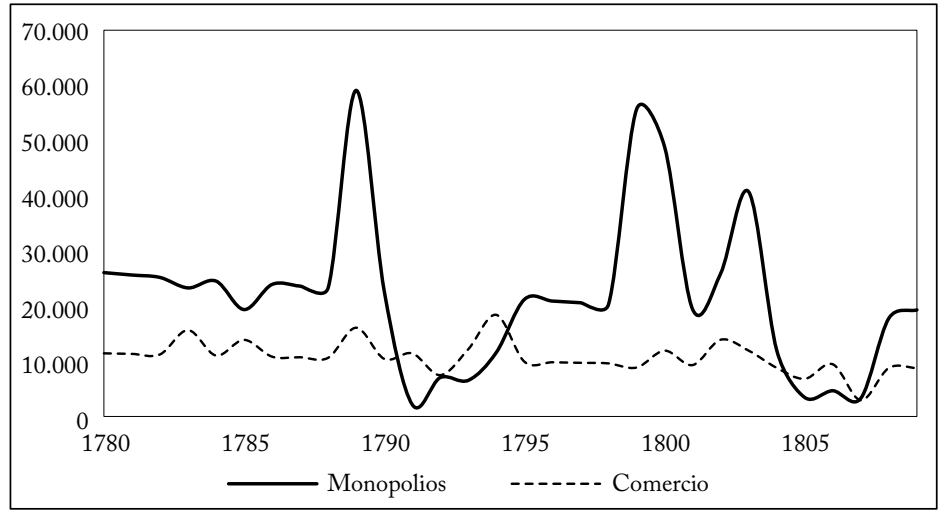

Fuente: Archivo General de la Nación, Sección Archivo, Anexo II, Fondo Real Hacienda Cuentas, Caja: 12, 44; Sección Archivo, Anexo III, Fondo Real Hacienda Cuentas, tomos 923c, 1206c 1288c, 1357c, 1410c, 1485c, 1666c, 1697c, 2437c, 2449c y 2437c; Sección Colonia, Fondo Real Hacienda, tomo 44; Sección Colonia, Fondo Real Hacienda Cartas, Legajo 14; elaboración propia.

A comienzos del periodo independentista la base económica de la región era la producción de tabaco y el comercio interno, lo que provocó graves distorsiones en el sector productivo, entre ellas la caída de la producción agrícola en Purificación y Neiva, los centros princi- 
pales de esta actividad (Brungardt, 1974). La producción tabacalera se resintió y experimentó una fuerte reducción hasta 1825, cuando se inicia una recuperación inducida por la reorganización del monopolio. Además, en las dos décadas anteriores a la eliminación del estanco, las expectativas de inversión ante los buenos precios internacionales y la iniciativa estatal de promover el acceso a capitales privados desde 1845 promovieron la concentración de la propiedad, la proletarización de pequeños cosecheros, que de ser arrendatarios pasaron a ser jornaleros al servicio de terratenientes, y un aumento significativo de la producción (Bejarano y Pulido, 1996, 122).

Con base en los cargos del monopolio, el restablecimiento del comercio interno terminada la guerra de independencia y la superación de la inestabilidad provocada por la separación de Ecuador y Venezuela, las finanzas de las provincias de Mariquita y Neiva recobraron una composición similar a la de finales del periodo colonial. Entre 1830 y 1845 , el $66 \%$ de los ingresos de Neiva provenía de los estancos, el 17\% de gravámenes comerciales y el 13\% del tributo indígena, mientras que el gobierno de Mariquita obtenía un 52\% por remisiones de Neiva y un 35\% por los estancos (Pinto, 2015).

La recuperación de la actividad tabacalera fue la base del auge exportador que viviría todo el país entre 1850 y 1876, bonanza en la que el distrito de Ambalema ocupó el primer lugar como productor entre 1845 y 1858, y luego fue desplazado por Santander (Bejarano y Pulido, 1986). El Estado Soberano del Tolima se fundaría sobre los rescoldos del auge tabacalero de Ambalema. Su mayor fuente de ingresos fiscales eran los gravámenes comerciales, los impuestos al consumo de licores y al sacrificio de ganado. Y se esperaba consolidar la contribución directa para sustituir los ingresos de ramos eliminados por el régimen liberal.

\section{ORDEN POLÍTICO Y ACTIVIDADES PRODUCTIVAS, 1861-1886}

E1 Estado Soberano del Tolima fue creado por decreto del 12 de abril de 1861 durante la guerra de los liberales caucanos comandados por Tomás Cipriano de Mosquera contra el gobierno conservador de Mariano Ospina Rodríguez. Vencieron los caucanos, que recibieron el apoyo de gran parte de los líderes políticos de las antiguas provincias de Mariquita y Honda, salvo de la ciudad de Neiva que fue tomada por las huestes liberales a la fuerza. E1 Estado apoyó de nuevo la gestión de Mosquera, quien en 1862 se dirigió al Cauca para poner fin a las intrigas pro conservadoras contra el gobierno liberal, fraguadas por Julio Arboleda (Ruiz, 2013, 544-545). 
Mapa 1

Estado Soberano del Tolima, 1863-1885

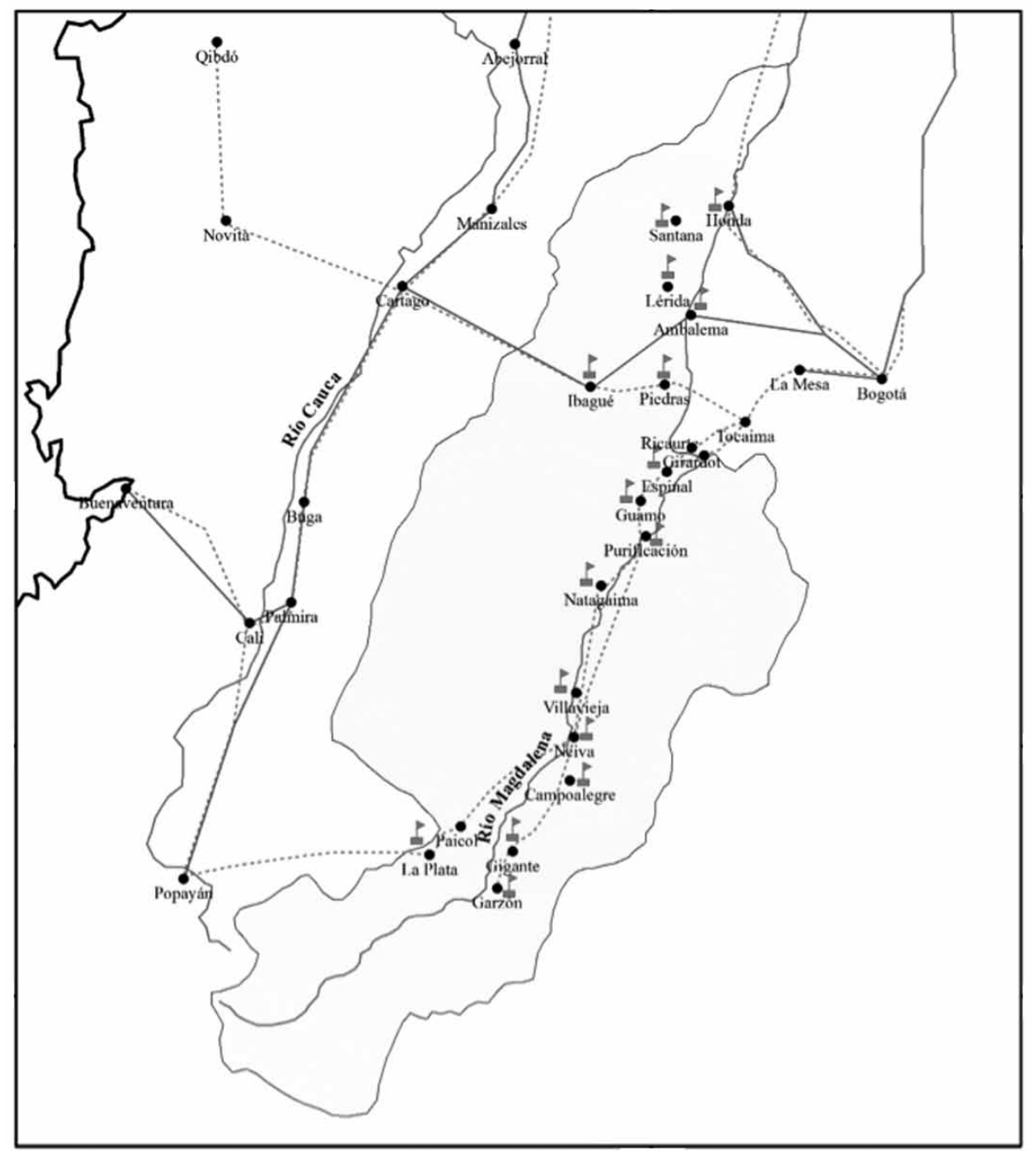

Fuente: Archivo General de la Nación, Sección Mapoteca 6, Ref. 123; elaboración propia.

Con la creación del Estado se buscaba unificar importantes centros urbanos: Neiva, con un desarrollo significativo por su ubicación estratégica y que comunicaba el suroccidente minero al centro del país; Honda, uno de los principales puertos internos, esencial en el transporte de mercancías importadas desde la costa norte; Ambalema, epicentro de la producción tabacalera, y Mariquita, cuyos yacimientos de plata y oro se habían intentado explotar desde hacía décadas. No obstante, la región no logró cohesionarse debido a la heterogeneidad 
geográfica, a la carencia de una estructura política dirigida por élites regionales definidas y a la escasez de vías de comunicación (Escobar, 2011, 52).

La división político-administrativa creó tres departamentos: el del norte, que en 1865 acogía el 19\% de la población y cuyos principales centros urbanos eran Ibagué, con 8.712 habitantes, y Guayabal, con 7.663 (Estado Soberano del Tolima, 1865a, 215). Su economía aún disfrutaba los efectos de la bonanza tabacalera recién finalizada y de la colonización antioqueña (Escobar, 2011, 55). En el departamento del centro vivía el 32\% de la población; sus centros principales urbanos eran Purificación, con 8.607 personas, y E1 Guamo, con 8.381 (Estado Soberano del Tolima, 1865a, 215), y su economía se basaba en la gran propiedad agrícola (Escobar, 2011, 55). El departamento del sur tenía el 49\% de la población; en Neiva habitaban 7.944 personas y en Aipe 5.070 (Estado Soberano del Tolima, 1865a, 215); y su actividad principal era la ganadería (Escobar, 2011, 55).

La escasa cohesión dificultaba el control del gobierno federal, y la presión burocrática provocó una amplia concentración de la tierra en la región en manos de comerciantes, burócratas y sociedades empresariales (Ramírez, 2011, 243). Aunque el Estado fue activo en la adjudicación de tierras, pues entre 1870 y 1874 otorgó 62.498 hectáreas y entre 1880 y 188464.399 hectáreas (Tovar, 1995, 145), solo otorgó 14 de esas 90 adjudicaciones a pequeños agricultores (Tovar, 1995, 147); 62.000 hectáreas quedaron en manos de 9 empresarios, 2.440 en poder de particulares y solo 11.000 en miles de habitantes de las aldeas de Fresno, Líbano. Murillo, Santo Domingo, Manzanares, Anaime y Herbeo (ibíd., 151). La mayor parte de esas tierras fueron entregadas a cambio de títulos de deuda, o a viejos latifundistas que las utilizaron para producir bienes agrícolas de consumo interno (ibíd). El efecto de la amañada adjudicación de baldíos en la concentración de la propiedad es evidente al calcular el índice de Gini para Ibagué con la misma metodología que emplearon Acemoglu et al. (2007) para el Estado Soberano de Cundinamarca.

Para nuestro ejercicio no pudimos reunir datos de todos los municipios por la dispersión de las fuentes; y solo calculamos ese índice para la ciudad de Ibagué, la capital durante el último periodo del Estado Soberano y del departamento del Tolima creado en 1886. El cálculo se hizo con datos de 307 propiedades con avalúos de $\$ 50$ a $\$ 10.000$, provenientes de la información sobre el cobro de contribuciones directas. El índice así calculado fue de 0,79 en 1894, superior al promedio del Estado Soberano de Cundinamarca. 
En ese contexto, la disputa por la adjudicación de baldíos y su papel en el aumento de la concentración de la tierra fueron el correlato de las principales compañías agrícolas creadas para controlar extensas áreas de bosques de quina, la cual estuvo en auge entre 1867-1873 y 1877-1882 debido al aumento de la demanda externa y su buen precio (Ocampo, 1984, 277). En la región, esa bonanza se mantuvo entre 1860 y 1870 , e, igual que la expectativa generada por el añil, llevó a crear empresas como la Compañía Colombiana de Quina en 1863, la Sociedad Pinzón Matiz en 1869, también exportadora de cacao, y la firma Aguirre y Compañía en la década de 1870 , todas con bajo capital y de efímera existencia (Moreno, 2013, 241-242). Otra actividad destacada fue la incipiente manufactura de sombreros de Suaza entre 1863 y 1876.

En 1879 el 79\% de la actividad agrícola se dedicaba a producir bienes de bajo valor unitario, de $\$ 1$ a $\$ 3$ la carga, en especial plátano, maíz y yuca. El valor de la panela era de $\$ 11$ la carga y representaba el 7\% de la producción; la miel, a $\$ 4$ la carga, representaba el 4\%. El producto más cotizado, la quina, a \$69 la carga, solo llegaba al 3\% (Díaz, 1879, 42-43).

La minería era otra rama esencial en la economía regional. En 1882 se explotaban 12 minas de oro en Santa Ana, Mariquita, Fresno y Guayabal, donde estaba la única mina de plata en funcionamiento (Pantoja, 1883, 56-58), mientras que en 1871 existían minas de plata en Órganos, Aipe, Pital, E1 Hato, Íquira, E1 Retiro, Guagua y La Plata, explotadas a veces por compañías extranjeras como la Tolima Mining Company Limited, fundada en 1871 (Moreno, 2013, 245-246). Entre 1877 y 1882 se registraron muchos denuncios de minas (Ramírez, 2000, 77), pero pocas produjeron los rendimientos esperados y casi todas se abandonaron (Ramírez, 1999, 77).

En la actividad ganadera, otro renglón destacado, el 56\% de la producción era de vacunos, el 16\% de cerdos y el 12\% de caprinos (Ramírez, 1879, 39-40). Esta fue una importante fuente de recursos para el Estado a través del impuesto de degüello, cuya mayor cantidad era aportada por el departamento del sur. Igual que la minería, la ganadería tuvo una fuerte tendencia a la baja, de más del $42 \%$, entre 1883 y 1886, como indica el número de reses beneficiadas (gráfica 2).

Una agricultura instalada en tierras de propiedad muy concentrada y dedicada a bienes de bajo valor, una minería con mayores expectativas que resultados y una ganadería en declive reflejan una economía con escaso potencial de crecimiento. La escasez de oportunidades económicas contribuyó a la disputa por las rentas del Estado, a veces de manera cruenta. Los dirigentes políticos captaban los gastos 
fiscales, así como el reparto de baldíos propiedad del gobierno, cuyo valor era de unos $\$ 29$ millones en $1879^{1}$, lo que generó un clima de inestabilidad política que provocó enfrentamientos armados entre distintas facciones de los partidos conservador y liberal.

Gráfica 2

Reses beneficiadas, 1883 y 1886

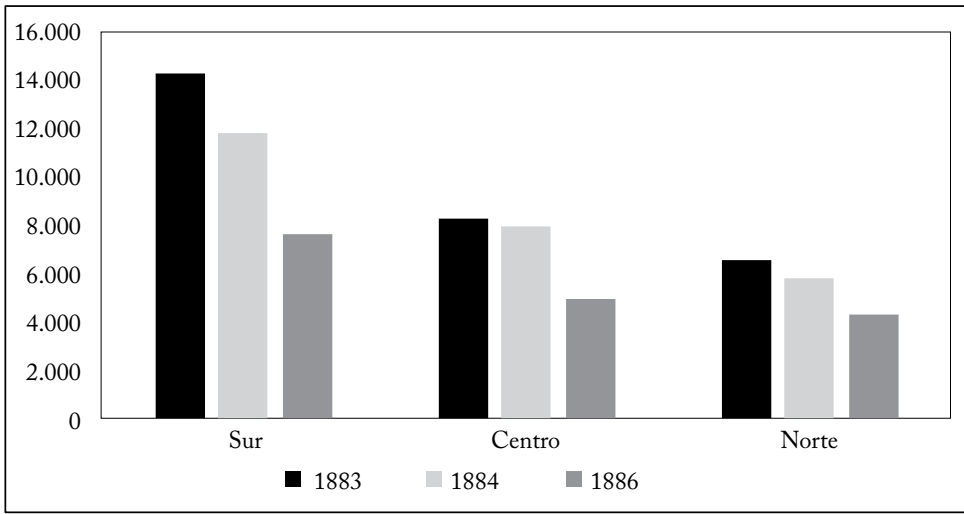

Fuente: Sicard $(1886,17)$.

Aunque no se puede constatar la alta concentración del poder político en toda la región por falta de datos confiables, empleando el método de Acemoglu et al. (2007) calculamos un índice para Ibagué del 79\% basado en el mantenimiento de sectores específicos en el manejo de la ciudad a través del cargo de alcaldes, con información extractada del listado elaborado por Bedoya (1991). Esta alta concentración política tuvo grandes efectos porque esta élite se opuso enérgicamente al cobro de la contribución directa y procuró fortalecer el impuesto de degüello, contra la del sur, dedicada a la ganadería. Además, en Ibagué se manejaba el presupuesto del Estado Soberano porque fue su capital durante varios periodos.

En la historia política del Estado Soberano del Tolima se distinguen tres periodos: el primero, entre 1863 y 1867, de gobiernos dirigidos por las élites liberales del sur; el segundo, entre 1867-1876, durante el cual mantienen el poder las élites conservadoras del norte; y el tercero, entre 1877 y 1885 , cuando los radicales liberales del norte y del sur se unifican y ejercen el poder sobre los conservadores (Moreno, 2013, 227). Las pugnas entre esos grupos provocaron gran inestabilidad institucional, como demuestra la promulgación de seis

${ }^{1}$ E1 39\% en el departamento del sur, el 36\% en el del norte y el $25 \%$ en el del centro (Ramírez, 1879, 15-16). 
constituciones en solo 24 años de existencia y el cambio de la capital al menos ocho veces, lo que dificultó la administración centralizada, pues el centro fluctuó entre Purificación, Neiva, Natagaima, Ibagué y Guamo (Ruiz, 2013, 544-546).

Este inestable clima legal y administrativo fue resultado de los continuos enfrentamientos armados que se libraron en el territorio del Estado desde su creación. En 1862 tuvo que aportar hombres y suministros para apoyar la campaña de pacificación del Cauca ante el levantamiento de Julio Arboleda; en 1865 las guerrillas conservadoras se levantaron contra el gobierno recién fundado (Ruiz, 2013, 545-546); en 1867, tras el derrocamiento de Mosquera, el liberalismo se dividió entre simpatizantes y enemigos del general, y en Ibagué se designó como presidente del Estado a Eugenio Castilla, crítico acervo del general caucano. El grupo favorable a Mosquera se levantó en Neiva encabezado por Timoleón Meza, gobernador del departamento del sur, el cual fue derrotado en noviembre de ese año, de modo que se consolidaron los conservadores del norte (Moreno, 2013, 228-229).

E1 Estado también sufrió las consecuencias de la guerra civil de 1876. Apoyó a los rebeldes del Cauca y Antioquia que se levantaron contra el gobierno nacional liberal; se libraron cuatro grandes batallas en su territorio, con 17.150 combatientes entre rebeldes y constitucionales (Borja, 2010, 304), y el resultado dio lugar al tercer periodo de su historia política, poniendo fin al control conservador. En 1884 los liberales que dirigían el gobierno del Estado se pronunciaron a favor del levantamiento de los radicales de Santander, se negaron a enviar los recursos y efectivos demandados por el presidente Núñez desde Bogotá, y el gobierno central respondió invadiendo el Tolima y liquidando el Estado Soberano en marzo de 1885.

Una economía en declive con períodos esporádicos de prosperidad, un orden institucional amenazado por las guerras y gobiernos inestables son el marco para entender la política fiscal del Estado Soberano del Tolima entre 1863 y 1885 . Esta respondía a los intereses de las élites que promovían una mayor concentración de la tierra sin contraprestación, a proyectos de liberación de la economía o a urgencias propias del continuo estado de guerra, y cambiaba al vaivén de los acontecimientos, como se verá a continuación.

\section{POLÍTICA FISCAL}

La política impositiva y de asignación del gasto se caracterizó por cambios continuos provocados por la situación política, los intereses de las élites y el comportamiento de la actividad económica. La ac- 
tividad legislativa se centraba en la contribución directa, el impuesto de degüello, el monopolio de licores, el papel sellado, los derechos de peaje, el paso de ríos, el crédito público, las hipotecas y registros, las mortuorias y los derechos de las salinas nacionales. Para el Estado Soberano se promulgaron ocho leyes orgánicas de hacienda y cinco reformas menores a cada una de ellas, cuyo contenido acerca de los rubros de recaudo más importantes es tema de esta sección.

Las principales fuentes de recaudo eran la contribución directa y el derecho de degüello, que aportaban el 53\% del ingreso total. Uno de los principales proyectos fiscales de los gobiernos liberales en América Latina después de la Independencia fue consolidar el impuesto directo y progresivo sobre la renta y la propiedad territorial, y Colombia no fue la excepción durante el periodo federal.

Con el fin de cubrir los gastos del Estado, la asamblea constituyente decretó en 1863 el recaudo del impuesto sobre riquezas superiores a $\$ 45.000$ (Estado Soberano del Tolima, 1863a, 28), eximiendo las contribuciones adeudadas hasta diciembre de 1861 (Estado Soberano del Tolima, 1863b, 29). En noviembre la asamblea decretó su carácter permanente, y estableció que los municipios tenían plena libertad para determinar el objeto a gravar y fijar los montos que debían recaudar. Pretendía evitar un elevado cobro por derechos de navegación en los ríos y de impuestos al consumo de bienes nacionales, conforme al espíritu liberal de no obstaculizar el comercio interno (Estado Soberano del Tolima, 1864b, 75). Este sistema se abandonó en 1877 y se obligó a los municipios a recaudar las sumas que les fuesen exigidas cobrando $\$ 6$ por cada $\$ 1.000$ de patrimonio (Estado Soberano del Tolima, 1877a, 215). Cabe mencionar, por último, que, como producto de la guerra de 1876 y los desajustes fiscales que provocó, a la contribución directa se adicionaron dos cuotas extraordinarias para cubrir los gastos atrasados de la milicia (Estado Soberano del Tolima, 1879a, 324- 325).

No obstante la importancia de la contribución directa y el interés de consolidar su cobro para basar el fisco en impuestos equitativos, su éxito fue parcial debido a varios factores, entre ellos la desmesurada presión de los grandes propietarios sobre las asambleas municipales encargadas de avaluar las propiedades para subvalorar sus bienes (Castilla, 1881, 8) y la negativa de los propietarios a pagar las sumas fijadas, así fuesen mínimas; de modo que gran parte de lo que se debía recaudar era consignado como deuda a favor del Estado con recargos por intereses, una opción que no era suficientemente coercitiva para asegurar el pago, y que llevó a promulgar rebajas y exenciones de intereses con pocos resultados (Pantoja, 1883, 13-14). 
Con la extensión de la ganadería de vacunos en el sur del Estado, los legisladores también determinaron las bases para cobrar el impuesto de degüello, y en 1863 se decidió cobrar $\$ 1$ por cada res sacrificada (Estado Soberano del Tolima, 1863c, 101), una medida que en 1865 se consideró agresiva y perjudicial para el desarrollo de la actividad, de modo que el cobro se redujo en un 50\% (Estado Soberano del Tolima, $1867 b, 156)$. Pero esta reducción no fue suficiente para frenar la baja de la producción en la década de 1880.

Otras fuentes de ingreso de las que se ocupó la actividad legislativa fueron los gravámenes a la producción, comercialización y consumo de licores, que aportaban el 16\% del recaudo. Una vez formado el Estado Soberano del Tolima, el gobierno liberal propuso restablecer el monopolio de producción del aguardiente para evitar el cobro de la contribución directa, propuesta que fue derogada en 1866 y solo estuvo vigente un año. Debido a la importancia de estos fondos para cubrir las necesidades del gobierno y ante la devaluación del precio del licor y la merma de su calidad, los legisladores, en una actitud reflexiva, decidieron en 1867 cobrar 5 centavos por cada litro destilado y 20 centavos por cada $\$ 50$ de licor vendido (Clavijo, 1993,59$)$, sistema que se mantuvo hasta 1876, cuando se restableció el monopolio de producción, que estuvo vigente hasta 1880 . En adelante se retomó el sistema de patentes de 1867 (ibíd., 60).

El crédito público también fue pieza clave en el cambiante sistema fiscal del Estado, debido a las urgencias provocadas por los déficits ocasionados por las guerras, la parálisis de actividades productivas y arreglos con otros estados por la adjudicación de baldíos. En 1863 la primera disposición adoptada para sostener al Estado, junto al cobro momentáneo de la contribución directa, fue autorizar al ejecutivo para hacer arreglos financieros con particulares (Estado Soberano del Tolima, 1863a), como los vales que en 1866 se aceptaron para el pago de rentas (Estado Soberano del Tolima, 1866, 228). Varias veces se recurrió a la emisión de vales de deuda: en 1868, por un valor de $\$ 40.000$ (Estado Soberano del Tolima, 1868a, 284), en 1869 por $\$ 15.000$ (Estado Soberano del Tolima, 1869a, 384), en 1870 por $\$ 13.000$ (Estado Soberano del Tolima, 1870, 395), en 1871 por $\$ 19.000$ (Estado Soberano del Tolima, 1871, 575) y en 1881 por $\$ 24.000$ (Estado Soberano del Tolima, 1881a, 288).

La organización y el reconocimiento de estas obligaciones solo se inició en 1869, cuando el Estado Soberano aceptó como deuda pagadera los servicios no cancelados entre 1864-1868, las deudas contraídas durante las revueltas de 1865 y 1868, los empréstitos y las 
emisiones de vales. Esas obligaciones serían pagadas con el producto de las mortuorias (impuesto a las herencias), con ingresos varios (provenientes de multas e intereses de deudores) y con $\$ 40.000$ reconocidos por Cundinamarca en 1866 por adjudicación de baldíos pertenecientes al Tolima (Estado Soberano del Tolima, 1869b, 407). En 1870 se redujeron los fondos específicos para el pago de deuda, y las mortuorias dejaron de destinarse para ese fin (Estado Soberano del Tolima, 1870b, 481).

También se fijaron contribuciones al servicio de correos, sobre el que se cobraba un derecho de 10 a 80 centavos, y al papel sellado, de 20 a 50 centavos (Estado Soberano del Tolima, 1863e, 677), que aportaban el 9,1\% del recaudo. Los impuestos al comercio, que sumaban el 8\% de los ingresos ordinarios, consistían en los derechos de consumo, derogados en 1863 (Ley 4 de noviembre de 1863); el peaje, $\$ 1$ por cada 125 kilogramos de mercancías exportadas y $\$ 2$ por cada 125 kilos de importaciones (Estado Soberano del Tolima, 1863e, 687); la introducción de ganado vacuno, $\$ 1$ por cada res (Estado Soberano del Tolima, 1863e, 685) y el pasaje de ríos.

Algunos tributos gravaron el comercio de la propiedad raíz, que aportaba el 6,3\% del recaudo, como los derechos de hipoteca y registro, 25 centavos por cada $\$ 100$ de todo contrato (Estado Soberano del Tolima, 1863d, 684), y las mortuorias, en las que se cobraba entre el 0,5\% y $15 \%$ de la herencia dependiendo del parentesco de los beneficiarios (Estado Soberano del Tolima, 1880a, 281-284). Los derechos sobre minas solo llegaron a aportar el $2 \%$.

Así, la política impositiva fue muy variable, sobre todo en los métodos de contabilidad y recaudo, debido al cambio continuo de la Constitución y al traslado de la capital del Estado, conforme a los intereses de las élites partidistas que detentaran el poder. La política fiscal buscó gravar la propiedad de la tierra que sustentaba la agricultura y la ganadería, las dos principales actividades económicas de la región, y protegerlas mediante derechos de peaje a la importación de bienes agrícolas dos veces mayores que los de las exportaciones, y derechos por la introducción de ganado. Los impuestos al comercio no solo buscaban proteger estas dos actividades sino que indicaban cierto grado de apertura, al eliminar el derecho de consumo. Los peajes y el cobro por paso de ríos y uso de caminos, más que aportar a los gastos generales del Estado, se dedicaban a mejorar las vías de comunicación. La actitud frente a la producción y venta de aguardiente fluctuó entre una estrategia monopólica y el cobro de patentes ante la oposición de pequeños productores y medianos empresarios contra el estanco. Los cobros por servicios de 
correo, papel sellado y timbre tenían como propósito su propio mantenimiento, mientras que los gravámenes a la minería poco aportaban debido al escaso desarrollo de esa actividad durante el periodo. Así como las características de la economía prefiguraron la política impositiva, el devenir de la guerra hizo necesario recurrir al crédito público mediante la emisión de vales y la fijación de sobrecargas en momentos de déficit. Los resultados de esta política impositiva solo se pueden apreciar cabalmente en términos cuantitativos, lo cual es tema de la siguiente sección.

\section{Dinámica y composición de los ingresos y egresos fiscales}

Aquí se analiza la composición y la dinámica de los ingresos y egresos del Estado entre 1863 y 1885, como aspectos dependientes de las características económicas, la evolución política y los cambios en las disposiciones fiscales del gobierno. Primero se describe la participación de los rubros de ingreso agrupados así: gravámenes a la propiedad (contribución directa), impuestos a la actividad pecuaria (degüello), a la producción y venta de bebidas alcohólicas, a los servicios del Estado (correos, timbre, papel sellado, rentas de colegios y cárceles), impuestos al comercio (introducción de ganado, consumo, peaje y pasaje de ríos), contribuciones del mercado de bienes inmuebles (mortuorias e hipotecas y registro), minería (registro e impuesto de minas), crédito y varios (venta y arrendamiento de bienes del Estado, contribución de guerra, aprovechamientos y venduta).

Gráfica 3

Ingresos fiscales, 1863-1885

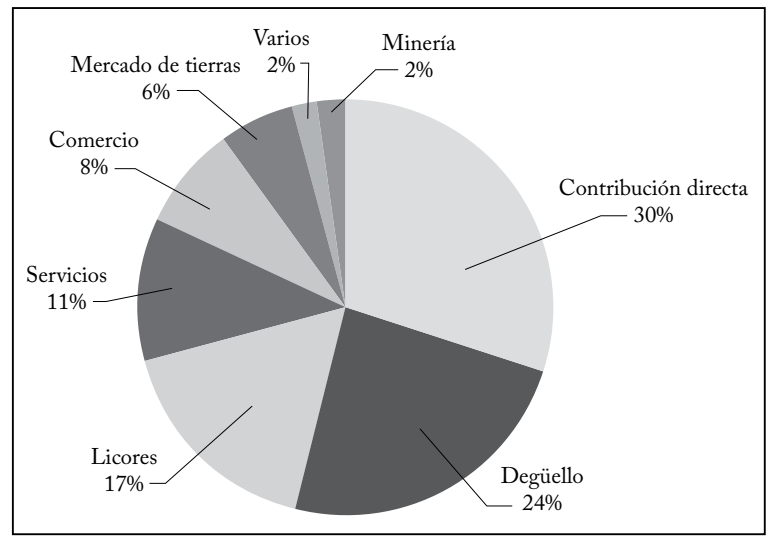

Fuente: Estado Soberano del Tolima (1863e, 1863f, 1864a, 1864b, 1865b, 1866b, 1866c, 1866d, 1866e, 1868a, 1868b, 1868c, 1869c, 1870c, 1871b, 1873b y 1875a); Secretaría de Hacienda del Estado Soberano del Tolima (1877a, 1877b, 1877c y 1877d); Díaz (1879); Pantoja (1883); Sicard (1886), y Castilla (1881); elaboración propia. 
Como ya se mencionó, la composición del ingreso fiscal del Estado reflejaba las características económicas de la región: alta concentración de tierras dedicadas a bienes de bajo valor para consumo interno y ganadería, escaso desarrollo de la actividad minera y manufacturera. En este contexto, los recaudos contabilizados entre 1863 y 1885 se repartían entre la contribución directa, el 30\% del total; el impuesto de degüello, el 24\%; los impuestos a la producción y distribución de bebidas alcohólicas, el 17\%; y los servicios del Estado, sobre todo el papel sellado y el correo. Los gravámenes al comercio solo aportaron el 8\%, debido a la supresión de los impuestos al consumo. Los peajes se destinaban a mejorar las vías de comunicación. Los impuestos a las transacciones de bienes raíces solo reportaron el 6\%, porque la mayoría de las propiedades se adquirió mediante adjudicación de baldíos a grupos empresariales y no en transacciones entre particulares. La minería aportó un recaudo muy bajo.

Gráfica 4

Evolución del ingreso fiscal, 1863-1885

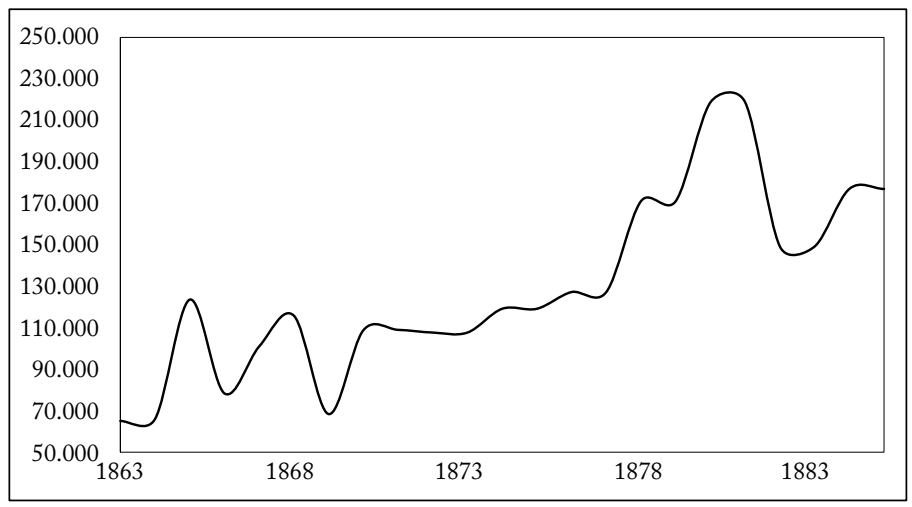

Fuente: Estado Soberano del Tolima (1863e, 1863f, 1864a, 1864b, 1865b, 1866b, 1866c, 1866d, 1866e, 1868a, 1868b, 1868c, 1869c, 1870c, 1871b, 1873b y 1875a); Secretaría de Hacienda del Estado Soberano del Tolima (1877a, 1877b, 1877c y 1877d); Díaz (1879); Pantoja (1883); Sicard (1886), y Castilla (1881); elaboración propia.

Entre 1863 y 1869 los ingresos tuvieron un comportamiento fluctuante a causa de las revueltas de 1865 y 1867 contra la elección como presidente del opositor a Mosquera, que provocaría la insurrección de Neiva y otro de los tantos cambios de capital. Después se produjo cierta estabilidad política, interrumpida por el inicio de la guerra civil nacional en 1876, que poco afectó el recaudo, el cual tendió a aumentar hasta 1881 porque el gobierno radical, de nuevo en el poder, eliminó la potestad de los municipios para fijar las cuotas de contri- 
bución directa y la monopolización de la producción de aguardiente. En general, el recaudo mostró un buen comportamiento de 1877 a 1882 , pues de unos $\$ 100.000$ que se recaudaban en los años sesenta se pasó a $\$ 218.000$ en 1880 . En 1871 Tolima recaudó más por habitante $(0,51)$ que Boyacá $(0,21)$ y Santander $(0,43)$. Desde 1881 se registró un leve descenso causado por la finalización de la participación en las utilidades de las salinas nacionales, la supresión del impuesto a la introducción de ganado, la caída de los flujos de comercio y, por tanto, sobre el derecho de peaje, debido al conflicto con el gobierno de Núñez y al hundimiento del recaudo por contribución directa por la subvaloración de las propiedades y la oposición al pago.

Gráfica 5

Ingreso fiscal de los tres principales rubros, 1863-1885

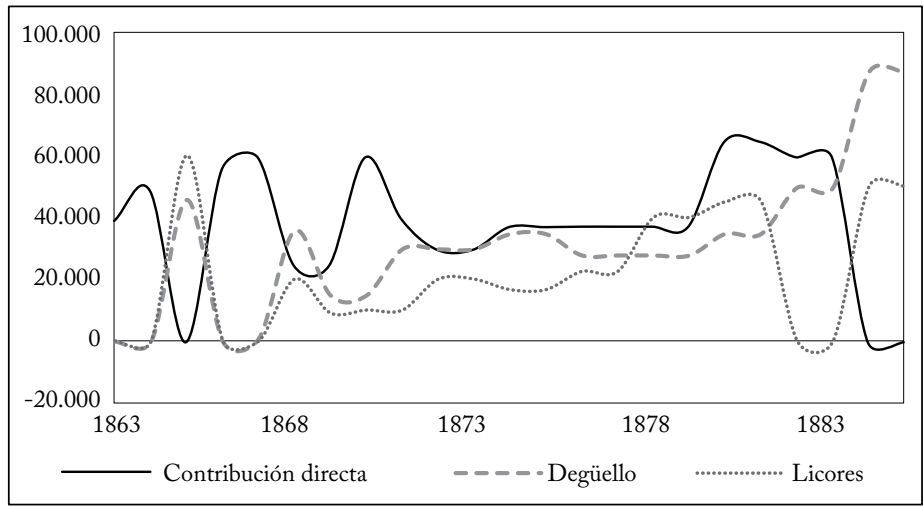

Fuente: Estado Soberano del Tolima (1863e, 1863f, 1864a, 1864b, 1865b, 1866b, 1866c, 1866d, 1866e, 1868a, 1868b, 1868c, 1869c, 1870c, 1871b, 1873b y 1875a); Secretaría de Hacienda del Estado Soberano del Tolima (1877a, 1877b, 1877c y 1877d); Díaz (1879); Pantoja (1883); Sicard (1886), y Castilla (1881); elaboración propia.

E1 impacto de las guerras y de la inestabilidad política, que suscitó continuas reformas fiscales, también se aprecia en la variación de los tres rubros de recaudo que aportaron el $71 \%$. La contribución directa fluctuó entre 1863 y 1872, y tuvo un crecimiento abrupto en 1880 por las sobrecargas para pagar las deudas de la guerra de 1876 y el retorno del control del recaudo al gobierno central. En 1884 el recaudo se desplomó a pesar de las exenciones al pago de intereses de los deudores, ante la negativa de los propietarios a pagarlos. E1 impuesto de degüello también fue muy volátil hasta 1865 , cuando el gobierno decidió rebajar el 50\% por res para evitar la evasión y debido al gran crecimiento de la ganadería en el sur, que trajo un aumento continuo de este recaudo. Pero se estancó a causa del des- 
censo del hato en todo el territorio entre 1883 y 1886 . E1 recaudo del impuesto a los licores fluctuó notablemente por influencia de la política impositiva: ascendió hasta 1865 cuando se estableció el sistema de patentes, creció en forma moderada y fue significativo en 1876, cuando la producción de aguardiente se volvió a monopolizar. En 1880 disminuyó por la liberación total de la producción y la distribución, retornando al comportamiento anterior cuando se restableció el sistema de patentes.

El análisis anterior confirma la hipótesis de una baja capacidad de recaudo que, pese a una mejoría durante el periodo, no fue suficiente para suplir las necesidades del gobierno, debido al estancamiento de actividades como la minería o la producción agrícola de bienes de alto valor para el mercado exterior. En ese contexto, en la composición predominaron los derechos sobre la gran propiedad, el consumo de bebidas alcohólicas y la ganadería. Las fluctuaciones fueron resultado de la inestabilidad política, los alzamientos armados y los cambios en la legislación.

Gráfica 6

Evolución del gasto fiscal, 1863-1885

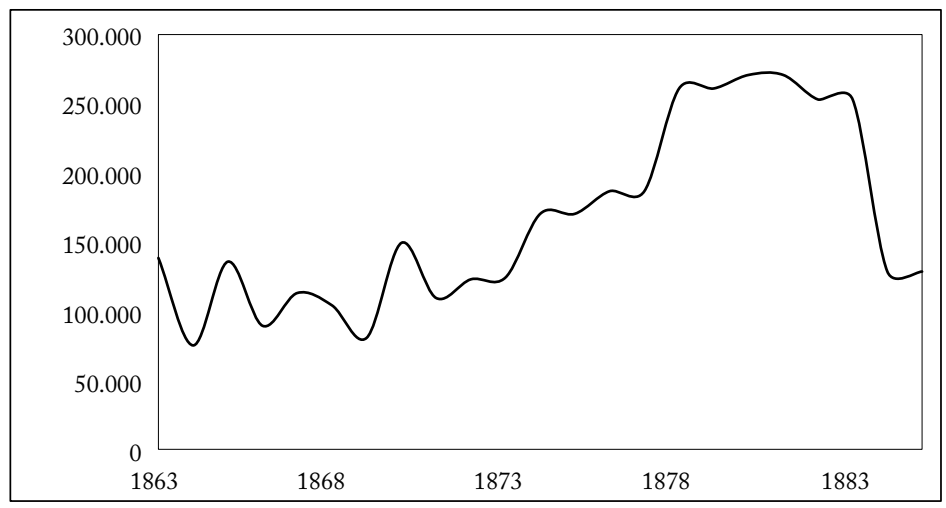

Fuente: Estado Soberano del Tolima (1863e, 1863f, 1864a, 1864b, 1865b, 1866b, 1866c, 1866d, 1866e, 1868a, 1868b, 1868c, 1869c, 1870c, 1871b, 1873b y 1875a); Secretaría de Hacienda del Estado Soberano del Tolima (1877a, 1877b, 1877c y 1877d); Díaz (1879); Pantoja (1883); Sicard (1886), y Castilla (1881); elaboración propia.

El comportamiento del gasto fue el siguiente: los egresos, igual que los ingresos, fluctuaron durante los primeros años, hasta la caída del gobierno liberal y el ascenso del norte conservador. Desde ese momento crecieron en forma continua, con un fuerte aumento después de la guerra civil de 1876 que elevó los gastos de fomento y milicia, pero en 1884 el gasto cayó notablemente con el recorte del personal 
administrativo. Este comportamiento se entiende mejor cuando se descompone por rubros, como se hace a continuación.

E1 gasto se puede descomponer en erogaciones burocráticas (justicia, hacienda, municipios y gobierno ejecutivo), gastos de milicia, servicio de deuda y fomento (obras públicas, instrucción y beneficencia). Como muestra la gráfica 6 , la mayor parte de los fondos se destinó a la burocracia: el $42 \%$ al poder judicial, el 19\% al ejecutivo, el $13 \%$ a la rama de hacienda y el $12 \%$ al régimen municipal. Los gastos de milicia fluctuaron conforme al vaivén de las guerras, los de fomento se concentraron en obras públicas -caminos y puentes-, el servicio de deuda solo copó el $3 \%$ ya que los fondos destinados a pagarla eran escasos y a veces se limitaron a los ingresos por multas e ingresos extraordinarios.

Gráfica 7

Composición del gasto, 1863-1885

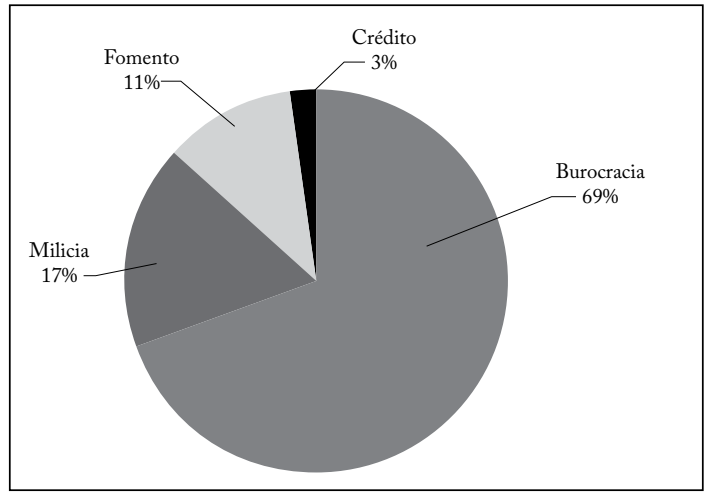

Fuente: Estado Soberano del Tolima (1863e, 1863f, 1864a, 1864b, 1865b, 1866b, 1866c, 1866d, 1866e, 1868a, 1868b, 1868c, 1869c, 1870c, 1871b, 1873b y 1875a); Secretaría de Hacienda del Estado Soberano del Tolima (1877a, 1877b, 1877c y 1877d); Díaz (1879); Pantoja (1883); Sicard (1886), y Castilla (1881); elaboración propia.

La evolución de los distintos ramos refleja el interés por consolidar un sólido aparato administrativo, rubro que creció en forma permanente hasta 1883, cuando se redujeron los encargados de la justicia y se eliminaron las remisiones del gobierno central para gastos municipales (gráfica 8). Los gastos de guerra entre 1861 y 1867 presentan dos picos: en 1865, por las revueltas de las guerrillas conservadoras, derrotadas por Mosquera, y en 1867, por la insurrección de los mosqueristas en Neiva, contra el presidente reconocido por Bogotá y residente en Ibagué. Se elevan de nuevo en 1870, por el pago de los servicios no reconocidos en ese conflicto. Ese gasto se mantiene estable, pero tiende 
a aumentar entre 1876 y 1878 durante la guerra federal que ganaron los radicales, que ya en el poder lograron estabilizarlo y reducirlo poco antes de la arremetida de la guardia nacional en 1885.

La estabilización y la caída del gasto militar después de la guerra federal permitieron aumentar los gastos de fomento, que se mantenían en un nivel muy bajo, sobre todo los de construcción de obras e instrucción pública. El servicio de deuda no fue un rubro significativo debido a los escasos fondos dedicados a ella, que incluían las mortuorias, las multas y $\$ 40.000$ que adeudaba Cundinamarca por baldíos adjudicados en Mariquita y Neiva, y no canceló.

Gráfica 8

Gasto por rubros, $1863-1885$

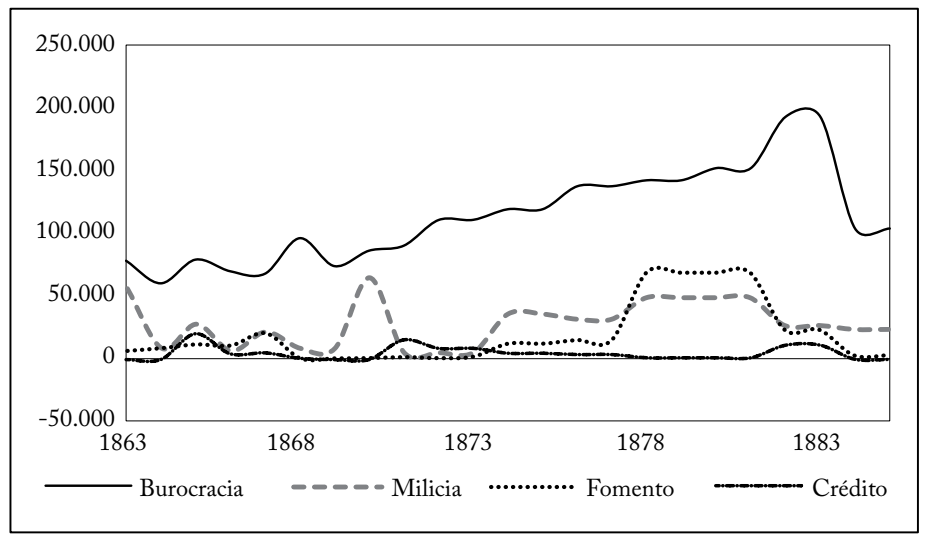

Fuente: Estado Soberano del Tolima (1863e, 1863f, 1864a, 1864b, 1865b, 1866b, 1866c, 1866d, 1866e, 1868a, 1868b, 1868c, 1869c, 1870c, 1871b, 1873b y 1875a); Secretaría de Hacienda del Estado Soberano del Tolima (1877a, 1877b, 1877c y 1877d); Díaz (1879); Pantoja (1883); Sicard (1886), y Castilla (1881); elaboración propia.

La educación como eje del desarrollo económico y cultural solo empezó a ser atendida en forma sistemática en la década de 1870, después de finalizar la guerra, lo cual hizo posible aumentar el número de centros educativos. En 1864 solo había 11 escuelas en un Estado que tenía 63 poblados, dos de ellas en Neiva, una para varones y otra para niñas, y dos colegios de secundaria: el Santa Librada y el San Simón. Solo había 460 estudiantes, entre unos 183.000 habitantes, de ellos 26.000 de 5 a 9 años de edad y 22.300 de 9 a 14 años, es decir, una cobertura de apenas 0,018\%. En 1870 ya había 42 escuelas, con 1.296 estudiantes, y en 1886, 87 escuelas y 92 maestros. E1 número de estudiantes aumentó paulatinamente, hasta 4.877 en 1883 . Suponiendo una edad escolar de 5 a 9 años, la cobertura creciente era 
insuficiente, del 7\% al 12\%, incluso en 1894 cuando llegó al 20\% de la población matriculada de esa edad. Si se cruza contra la población de 4 a 15 años, la cifra se reduce aún más, del $4 \%$ en 1835 a solo un $11 \%$ en 1894, muy baja en comparación con la de algunos países europeos en esa misma época: el 72\% en Francia y el 35\% en Italia. Frente al promedio colombiano, Tolima, ya como departamento, lo superó en 1891 ( $2,8 \%$ de su población), aunque era uno de los más atrasados antes de iniciar la etapa federal en 1851 (menos del 1\% de su población).

Las guerras, la alta concentración de la propiedad y del poder político, la debilidad del sector productivo y la escasez de recursos federales impidieron que los radicales liberales alcanzaran los índices que lograría el conservatismo de la época regeneradora, aunque las bases de ese impulso se construyeron en la década de 1870 con el aumento del presupuesto de fomento en tiempos de paz. Varios factores hicieron posible que Tolima superara la cobertura nacional promedio en 1891: 1) el gobierno nacional aportaba el 11\% del gasto para materiales y funcionamiento de las oficinas de inspección, que fueron reorganizadas y mejoraron la eficiencia; 2) el departamento aportaba el $26 \%$ para pagar al personal de las escuelas de varones y rurales; 3) los municipios, con sus propias rentas, utilidades de capitales prestados a interés o usufructo de bienes públicos y donaciones individuales, suplían el 63\% del gasto total para compra de material en escuelas de niñas, gastos de personal docente y sobresueldos a los directores (Caicedo, 1890), y 4) la pacificación y la estabilidad política impulsada por el gobierno conservador se mantuvo durante 14 años, hasta 1899, cuando estalló la Guerra de los Mil Días, pues la de 1895-1896 solo duró dos meses y se concentró en Cundinamarca y Santander. La mayor ayuda del gobierno central, el papel más protagónico de las comunidades vigiladas por la Iglesia y la consolidación del sistema de inspección y vigilancia, además del largo periodo de paz, permitieron aumentar el presupuesto y la cobertura educativa, una tarea que no solo se consideró como una empresa económica sino como una obra civilizatoria durante la Regeneración.

El fisco del Estado Soberano del Tolima se basó en la agricultura para consumo interno y la ganadería en tierras de propiedad muy concentrada, agravada por la adjudicación de baldíos, que fortaleció a las élites locales que pugnaban por el poder político, en un clima de inestabilidad que provocó guerras frecuentes y cambios legislativos. Los escasos ingresos del impuesto directo, del degüello y del consumo de licores dejaban pocos fondos para consolidar un aparato militar 
capaz de imponer el orden o para crear una estructura burocrático administrativa que aumentara los ingresos fiscales, escasez que se agravaba en tiempos de guerra cuando el gasto militar aumentaba, reduciendo aún más los fondos para fomento y obligando a recurrir a préstamos forzosos y voluntarios, que en su mayoría dejaron de pagarse. En un contexto de alta inequidad política y económica, la educación como vehículo para contrarrestarla solo tuvo avances importantes en la década de 1870 y, después de la experiencia federal, debido a una mejor administración y a la estabilidad política que solo duró hasta 1899.

E1 Estado Soberano tenía sus días contados. En 1885 la situación se hizo insostenible porque mantuvo las banderas radicales contra un gobierno central cada vez más fuerte, apoyado por la guardia nacional, la cual derrotó a las fuerzas federales pocos meses después de que el Tolima respaldara a los radicales de Santander, fuerzas que no tenían mucha acogida entre los grandes propietarios, opuestos a la contribución directa, ni entre los ganaderos, contrarios al derecho de degüello, ni entre el pueblo, que rechazaba el gravamen al aguardiente.

\section{CONCLUSIONES}

Este artículo analiza la evolución y la composición de los ingresos y gastos del Estado Soberano del Tolima como aspectos dependientes de sus actividades económicas y de la estabilidad política entre 1863 y 1885 . Se constató que durante el periodo colonial se consolidaron la producción tabacalera en Ambalema y el comercio en Honda, el punto de comunicación entre el litoral atlántico y la región central, que decayeron durante la Independentista y se recuperaron entre 1830 y 1863. Durante el periodo federal, la actividad económica se centró en la ganadería y la producción de bienes agrícolas para consumo interno, salvo la quina y el añil que tuvieron breves auges en el mercado internacional, con un escaso desarrollo de la minería y la manufactura. En el plano político, la integración de una región con una población dispersa, sin vías de comunicación, sin élites regionales bien definidas y en un marco de pugnas partidistas suscitó revueltas internas, como las de 1865 y 1867, y agravó el impacto de las guerras federales de 1876 y 1884 . Esas confrontaciones impidieron la centralización de la autoridad fiscal, debido al cambio continuo de la capital y a los cambios permanentes de política tributaria. Además, se constató que la adjudicación de baldíos, en vez de democratizar la propiedad, la concentró y generó alta inequidad, como muestra un índice de Gini de 0,7 para Ibagué en 1894, acompañada de una fuerte concentración 
política a nivel local, un hecho esencial para entender las pugnas que avivarían las guerras; ejercicio que habrá de complementarse con cálculos similares para todos los municipios del Estado.

En ese contexto, los ingresos fiscales provenían de impuestos directos a la propiedad, el degüello y el monopolio o el cobro de patentes por la fabricación o distribución de bebidas alcohólicas; con la oposición de los grandes propietarios que presionaban a las juntas encargadas de fijar las cuotas de la contribución, de los productores de aguardiente y de los ganaderos del departamento del sur. La oposición, el cambiante orden fiscal y las guerras afectaron el recaudo e hicieron fluctuar los ingresos, que solo se estabilizaron entre 1876 y 1885, el último periodo de existencia del Estado, como consecuencia de las reformas realizadas por el gobierno liberal radical.

Debido a los bajos ingresos y a su inestabilidad, la mayoría de los fondos se destinó a organizar la burocracia y fortalecer el aparato militar en tiempos de guerra, dejando poco dinero para invertir en fomento y cubrir las obligaciones financieras. Por ello, solo en la década de 1870, durante el breve periodo de paz y acceso al poder de los radicales, se pudo aumentar la cobertura educativa y sentar las bases del gran impulso que tendría en el periodo regenerador.

E1 Estado Soberano del Tolima fue débil en términos financieros y no fue capaz de legitimar su poder asignando gastos para el fomento de las comunidades, como la educación, empresa que inició tardíamente. Sus mandatarios intentaron fortalecer la burocracia y el aparato de justicia del Estado, sin una fuerza militar capaz de hacer frente al reto de pronunciarse a favor del Estado Soberano de Santander en la conflagración de 1885 y contra el gobierno de Núñez, quien no dudó en usar la fuerza para acabar con el proyecto federal.

\section{REFERENCIAS BIBLIOGRÁFICAS}

\section{Fuentes de archivo}

Archivo General de la Nación

Sección Archivo Anexo iI, Fondo Real Hacienda Cuentas, Caja 12, 44.

Sección Archivo Anexo ini, Fondo Real Hacienda Cuentas, tomos 923c, 1206c 1288c, 1357c, 1410c, 1485c, 1666c, 1697c, 2437c, 2449c y 2437c.

Sección Colonia, Fondo Real Hacienda, tomo 44.

Sección Colonia, Fondo Real Hacienda Cartas, Legajo 14.

Sección Mapoteca 6, Ref. 123.

Archivo Histórico de Ibagué

Sección República, tomo 113, Documento 24. 


\section{Fuentes impresas}

1. Acemoglu, D. et al. "Economic and political inequality in development: The case of Cundinamarca, Colombia", NBER working paper 13208, 2007.

2. Bedoya, J. Compendio de historia de Ibagué y del Tolima, Ibagué, Imprenta Departamental, 1991.

3. Borja, M. Espacio y guerra. Colombia federal, 1858-1885, Bogotá, Universidad Nacional de Colombia, 2010.

4. Brewer, J. The sinews of power: War, money, and the English State, 1688-1783, Cambridge, Harvard University Press, 1990.

5. Brungardt, M. P. "Tithe production and patterns of economic change in central Colombia, 1764-1833", tesis de doctorado, University of Texas, Austin, 1974.

6. Caicedo, H. Informe del Inspector General de Instrucción Pública, Ibagué, Imprenta del Departamento, 1890.

7. Castilla, E. Informe del Secretario de Hacienda al ciudadano Presidente del Estado Soberano del Tolima, Neiva, Imprenta del Estado, 1881.

8. Clavijo, H. Formación histórica de las elites locales en el Tolima, Bogotá, Banco Popular, 1993.

9. Clavijo, H. "Monopolio fiscal y guerras civiles en el Tolima, 18651899”, Boletín Cultural y Bibliográfico 30, 32, 1993, pp. 53-76.

10. Cortés C., R. y G. T. McCandless. "Argentina: From Colony to Nation. Fiscal and monetary experiences from the Eighteenth and Nineteenth Centuries", M. D. Bordo et al., eds., Transferring wealth and power from the Old to the New World: Monetary and fiscal institutions in the 17th through the 19th Centuries, Cambridge, Cambridge University Press, 2006, pp. 378-413.

11. Díaz, L. Informe del Secretario de Hacienda al ciudadano Presidente del Estado Soberano del Tolima, Neiva, Imprenta de Pedro Martínez, 1879.

12. Escobar, B. "De los conflictos locales a la guerra civil. Tolima, Colombia, a finales del siglo xıx”, tesis de doctorado, Ludwig-MaximiliansUniversität, Múnich, 2011.

13. Escobar, B. De los conflictos locales a la guerra civil. Tolima a finales del siglo xix, Bogotá, Academia Colombiana de Historia, 2013.

14. Estado Soberano del Tolima. Ley del 8 de enero de 1863, A. Rojas, ed., Registro oficial del Estado del Tolima. Compilación de las disposiciones ejecutivas de carácter permanente y general, expedidas hasta el 31 de diciembre de 1882, Neiva, edición oficial, 1863a, p. 28.

15. Estado Soberano del Tolima. Ley del 7 de febrero de 1863, A. Rojas, ed., Registro oficial del Estado del Tolima. Compilación de las disposiciones ejecutivas de carácter permanente y general, expedidas hasta el 31 de diciembre de 1882, Neiva, edición oficial, 1863b, p. 30.

16. Estado Soberano del Tolima. Ley de 6 de noviembre de 1863, J. Herrera, ed., Recopilación de actos legislativos del Estado Soberano del Tolima expedidos desde el año de 1862 hasta el de 1877, Bogotá, edición oficial, 1863 c, p. 101.

17. Estado Soberano del Tolima. Ley del 4 de noviembre de 1863, A. Rojas, ed., Registro oficial del Estado del Tolima. Compilación de las 
disposiciones ejecutivas de carácter permanente y general, expedidas hasta el 31 de diciembre de 1882, Neiva, edición oficial, Neiva, 1863d, p. 95.

18. Estado Soberano del Tolima. Ley de 2 de marzo de 1863, J. Herrera, ed., Recopilación de actos legislativos del Estado Soberano del Tolima expedidos desde el año de 1862 hasta el de 1877, Bogotá, edición oficial, $1863 \mathrm{e}$, pp. 66-72.

19. Estado Soberano del Tolima. Ley de 17 de noviembre de 1863, J. Herrera, ed., Recopilación de actos legislativos del Estado Soberano del Tolima expedidos desde el año de 1862 hasta el de 1877, Bogotá, edición oficial, 1863f, pp. 105-109.

20. Estado Soberano del Tolima. Ley de 3 de marzo de 1864, J. Herrera, ed., Recopilación de actos legislativos del Estado Soberano del Tolima expedidos desde el año de 1862 hasta el de 1877, Bogotá, edición oficial, 1864a, pp. 116-118.

21. Estado Soberano del Tolima. Ley del 30 de mayo de 1864, J. Herrera, ed., Recopilación de actos legislativos del Estado Soberano del Tolima expedidos desde el año de 1862 hasta el de 1877, Bogotá, edición oficial, 1864b, pp. 64-69.

22. Estado Soberano del Tolima. Ley del 30 de mayo de 1864, J. Herrera, ed., Recopilación de actos legislativos del Estado Soberano del Tolima expedidos desde el año de 1862 hasta el de 1877, Bogotá, edición oficial, 1864c, pp. 127-134.

23. Estado Soberano del Tolima. Censo de población de 1865, J. Herrera, ed., Recopilación de actos legislativos del Estado Soberano del Tolima expedidos desde el año de 1862 hasta el de 1877, Bogotá, edición oficial, 1865 a, pp. 215.

24. Estado Soberano del Tolima. Ley del 25 de enero de 1865, J. Herrera, ed., Recopilación de actos legislativos del Estado Soberano del Tolima expedidos desde el año de 1862 hasta el de 1877, Bogotá, edición oficial, 1865 b, pp. 176-187.

25. Estado Soberano del Tolima. Ley del 1 de agosto de 1866, A. Rojas, ed., Registro oficial del Estado del Tolima. Compilación de las disposiciones ejecutivas de carácter permanente y general, expedidas hasta el 31 de diciembre de 1882, Bogotá, edición oficial, 1866a, p. 228.

26. Estado Soberano del Tolima. Ley del 26 de enero de 1866, J. Herrera, ed., Recopilación de actos legislativos del Estado Soberano del Tolima expedidos desde el año de 1862 hasta el de 1877, Bogotá, edición oficial, 1866b, pp. 199-200.

27. Estado Soberano del Tolima. Ley del 1 de febrero de 1866, J. Herrera, ed., Recopilación de actos legislativos del Estado Soberano del Tolima expedidos desde el año de 1862 hasta el de 1877, Bogotá, edición oficial, 1866c, pp. 207-214.

28. Estado Soberano del Tolima. Ley del 9 de agosto de 1866, J. Herrera, ed., Recopilación de actos legislativos del Estado Soberano del Tolima expedidos desde el año de 1862 hasta el de 1877, Bogotá, edición oficial, 1866d, pp. 239-340.

29. Estado Soberano del Tolima. Ley del 12 de agosto de 1866, J. Herrera, ed., Recopilación de actos legislativos del Estado Soberano del Tolima 
expedidos desde el año de 1862 hasta el de 1877, Bogotá, edición oficial, 1866e, pp. 260-266.

30. Estado Soberano del Tolima. Ley de 25 de enero de 1865, J. Herrera, ed., Recopilación de actos legislativos del Estado Soberano del Tolima expedidos desde el año de 1862 hasta el de 1877, Bogotá, edición oficial, 1867a, pp. 156-176.

31. Estado Soberano del Tolima. Ley del 15 de enero de 1868, A. Rojas, ed., Registro oficial del Estado del Tolima. Compilación de las disposiciones ejecutivas de carácter permanente y general, expedidas hasta el 31 de diciembre de 1882, Neiva, edición oficial, 1868a, p. 284.

32. Estado Soberano del Tolima. Ley del 27 de enero de 1868, J. Herrera, ed., Recopilación de actos legislativos del Estado Soberano del Tolima expedidos desde el año de 1862 hasta el de 1877, Bogotá, edición oficial, 1868b, pp. 323-324.

33. Estado Soberano del Tolima. Ley del 27 de enero de 1868, J. Herrera, ed., Recopilación de actos legislativos del Estado Soberano del Tolima expedidos desde el año de 1862 hasta el de 1877, Bogotá, edición oficial, 1868c, pp. 346-351.

34. Estado Soberano del Tolima. Ley del 25 de noviembre de 1868, J. Herrera, ed., Recopilación de actos legislativos del Estado Soberano del Tolima expedidos desde el año de 1862 hasta el de 1877, Bogotá, edición oficial, 1868d, pp. 386-391.

35. Estado Soberano del Tolima. Ley de 8 de noviembre de 1869, A. Rojas, ed., Registro oficial del Estado del Tolima. Compilación de las disposiciones ejecutivas de carácter permanente y general, expedidas hasta el 31 de diciembre de 1882, Neiva, edición oficial, 1869a, p. 394.

36. Estado Soberano del Tolima. Ley del 20 de noviembre de 1869, J. Herrera, ed., Recopilación de actos legislativos del Estado Soberano del Tolima expedidos desde el año de 1862 hasta el de 1877, Bogotá, edición oficial, 1869b, pp. 406-408.

37. Estado Soberano del Tolima. Ley del 28 de noviembre de 1869, J. Herrera, ed., Recopilación de actos legislativos del Estado Soberano del Tolima expedidos desde el año de 1862 hasta el de 1877, Bogotá, edición oficial, 1869c, pp. 423-430.

38. Estado Soberano del Tolima. Ley del 22 de octubre de 1870, A. Rojas, ed., Registro oficial del Estado del Tolima. Compilación de las disposiciones ejecutivas de carácter permanente y general, expedidas hasta el 31 de diciembre de 1882, Neiva, edición oficial, 1870a, p. 395.

39. Estado Soberano del Tolima. Ley del 1 de diciembre de 1870, J. Herrera, ed., Recopilación de actos legislativos del Estado Soberano del Tolima expedidos desde el año de 1862 hasta el de 1877, Bogotá, edición oficial, 1870 b, p. 481.

40. Estado Soberano del Tolima. Ley del 1 de diciembre de 1870, J. Herrera, ed., Recopilación de actos legislativos del Estado Soberano del Tolima expedidos desde el año de 1862 hasta el de 1877, Bogotá, edición oficial, 1870c, pp. 487-493.

41. Estado Soberano del Tolima. Ley de 14 de noviembre de 1870, J. Herrera, ed., Recopilación de actos legislativos del Estado Soberano del 
Tolima expedidos desde el año de 1862 hasta el de 1877, Bogotá, edición oficial, 1871b, pp. 619-625.

42. Estado Soberano del Tolima. Ley del 14 de noviembre de 1873, J. Herrera, ed., Recopilación de actos legislativos del Estado Soberano del Tolima expedidos desde el año de 1862 hasta el de 1877, Bogotá, edición oficial, 1873a, pp. 677-856.

43. Estado Soberano del Tolima. Ley del 11 de noviembre de 1873, J. Herrera, ed., Recopilación de actos legislativos del Estado Soberano del Tolima expedidos desde el año de 1862 hasta el de 1877, Bogotá, edición oficial, 1873b, pp. 670-676.

44. Estado Soberano del Tolima. Ley de 13 de noviembre de 1875, J. Herrera, ed., Recopilación de actos legislativos del Estado Soberano del Tolima expedidos desde el año de 1862 hasta el de 1877, Bogotá, edición oficial, 1875a, pp. 856-863.

45. Estado Soberano del Tolima. Ley 21 de 1877. A. Rojas, ed., Registro oficial del Estado del Tolima. Compilación de las disposiciones ejecutivas de carácter permanente y general, expedidas hasta el 31 de diciembre de 1882, Neiva, edición oficial, 1877a, p. 578.

46. Estado Soberano del Tolima. Ley del 18 de julio de 1879, A. Rojas, ed., Registro oficial del Estado del Tolima. Compilación de las disposiciones ejecutivas de carácter permanente y general, expedidas hasta el 31 de diciembre de 1882, Neiva, edición oficial, 1879a, pp. 324-325.

47. Estado Soberano del Tolima. Decreto del 20 de octubre de 1880, A. Rojas,, ed., Registro oficial del Estado del Tolima. Compilación de las disposiciones ejecutivas de carácter permanente y general, expedidas hasta el 31 de diciembre de 1882, Neiva, edición oficial, 1880a, pp. 235-245.

48. Estado Soberano del Tolima. Decreto del 25 de diciembre de 1881, A. Rojas, ed., Registro oficial del Estado del Tolima. Compilación de las disposiciones ejecutivas de carácter permanente y general, expedidas hasta el 31 de diciembre de 1882, Neiva, edición oficial, 1881a, pp. 288-290.

49. Estado Soberano del Tolima. Ley del 20 de octubre de 1871, A. Rojas, ed., Registro oficial del Estado del Tolima. Compilación de las disposiciones ejecutivas de carácter permanente y general, expedidas hasta el 31 de diciembre de 1882, Neiva, edición oficial, 1871a, p. 575.

50. González, M. Ensayos de historia colonial colombiana, Bogotá, Punto de Lectura, 2005.

51. Halperin D., T. Guerra y finanzas en los orígenes del Estado argentino 1791-1850, Buenos Aires, Prometeo Libros, 2005.

52. Hernández J., J. La formación de la hacienda pública mexicana y las tensiones centro-periferia, 1821-1835, México DF, E1 Colegio de México, Instituto de Investigaciones Dr. José María Luis Mora y unAM, 2013.

53. Jara, A. y J. Tepaske. The royal treasuries of Spanish empire in America, vol. 4, "Ecuador", Durham, Duke University Press, 1990.

54. Junguito, R. "Las finanzas públicas en el siglo xix", A. Meisel y M. Ramirez, eds., Economía colombiana del siglo xix, Bogotá, Banco de la República y Fondo de Cultura Económica, 2010, pp. 41-136.

55. Kalmanovitz, S. "El federalismo y la fiscalidad del Estado Soberano de Panamá, 1850-1886", Revista de Economía Institucional 14, 27, 2012, pp. 99-145. 
56. Kalmanovitz, S. y E. López. "Las finanzas públicas de la Confederación Granadina y los Estados Unidos de Colombia, 1850-1886", Revista de Economía Institucional 12, 23, 2010, pp. 199-228.

57. López, E. y A. Castillo. "Federalismo y reformas institucionales en Cundinamarca 1848-1890", 2012, [www.utadeo.edu.co/files/collections/ documents/field_attached_file/federalismo_reformas_institucionales_ cundinamarca.pdf?width $=740 \&$ \&height $=780 \&$ \&inline $=$ true $]$.

58. Marichal, C. La bancarrota del virreinato: Nueva España y las finanzas del Imperio español, 1780-1810, México DF, Fondo de Cultura Económica, 1999.

59. Marichal, C. y M. Carmagnani. "From colonial fiscal regime to liberal financial order, 1750-1912”, M. D. Bordo et al., eds., Transferring wealth and power from the Old to the New World: Monetary and fiscal institutions in the 17th through the 19th Centuries, Cambridge, Cambridge University Press, 2006, pp. 284-326.

60. Marichal C. y J. Grafenstein, eds. "Introducción”, El secreto del imperio español: los situados coloniales en el siglo xviii, México DF, El Colegio de México e Instituto de Investigaciones Dr. José María Luis Mora, 2012, pp. 9-31.

61. Meisel, A. "Crecimiento, mestizaje y presión fiscal en el Virreinato de la Nueva Granada, 1761-1800”, Cuadernos de Historia Económica y Empresarial 28, 2011, pp. 1-97.

62. Meisel, A. "El situado de Cartagena de Indias a fines del siglo de las luces”, C. Marichal y J. Grafenstein, eds., El secreto del imperio español: los situados coloniales en el siglo xviii, México DF, El Colegio de México e Instituto de Investigaciones Dr. José María Luis Mora, 2012, pp. 193-212.

63. Moreno, D. "Neiva, capital del Estado Soberano del Tolima”, B. Tovar y R. Salas, eds., Historia comprehensiva de Neiva, t. II, Neiva, Alcaldía de Neiva, Academia Huilense de Historia y Secretaría Municipal de Cultura y Turismo, 2013, pp. 221-250.

64. Ocampo, J. A. Colombia y la economía mundial, 1830-1910, Bogotá, Siglo XXI y Fesarrollo, 1984.

65. Pantoja, R. Informe del Secretario de Hacienda al ciudadano Presidente del Estado Soberano del Tolima, Neiva, Imprenta del Estado, 1883.

66. Pico, C. M. "Fiscalidad bajo el dominio liberal en el Estado Soberano de Santander 1865-1879: un análisis de economía política”, tesis de maestría, Bogotá, Universidad Nacional de Colombia, 2011.

67. Pinto, J. “Finanzas de la República de Colombia, 1819-1830”, tesis de maestría, Bogotá, Universidad Nacional de Colombia, 2011.

68. Pinto, J. "Entre colonia y república. Fiscalidad en Ecuador, Colombia y Venezuela, 1780-1845", tesis de doctorado, Bogotá, Universidad Nacional de Colombia, 2015.

69. Ramírez, R. "De la distribución de baldíos a la consolidación de una región cafetera: dinámica comercial y estructuras agrarias en el Líbano-Tolima, 1866-1897”, Anuario Colombiano de Historia Social y de la Cultura 26, 2000, pp. 83-113.

70. Ramírez, R. “La fundación del Líbano-Tolima 1849-1886”, Anuario Colombiano de Historia Social y de la Cultura 30, 2003, pp. 239-255. 
71. Rodríguez, O. “La caja real de Popayán, 1738-1800”, Anuario Colombiano de Historia Social y de la Cultura 15, 1987, pp. 5-36.

72. Ruiz, J. "Guerra y política en la Neiva decimonónica. Fin de siglo y batalla de Matamundo", B. Tovar y R. Salas, eds., Historia comprehensiva de Neiva, t. II, Neiva, Alcaldía de Neiva, Academia Huilense de Historia y Secretaría Municipal de Cultura y Turismo, 2013, pp. 537-571.

73. Sánchez S., E. Las alcabalas mexicanas 1821-1857. Los dilemas en la construcción de la Hacienda nacional, México DF, Instituto de Investigaciones Dr. José María Luis Mora, 2009.

74. Sánchez S., E. Corte de caja. La reforma fiscal de Nueva España y el primer reformismo fiscal de los borbones 1720-1755. Alcances y contradicciones, México DF, Instituto de Investigaciones Dr. José María Luis Mora, 2013.

75. Santilli, D. V. "E1 papel de la tributación en la formación del Estado. La contribución directa en el siglo xix en Buenos Aires”, América Latina en la Historia Económica 33, 2010, pp. 30-63.

76. Secretaría de Hacienda del Estado Soberano del Tolima. "Cuentas del Estado Soberano del Tolima”, Gaceta del Tolima 33, 1877a, p. 1.

77. Secretaría de Hacienda del Estado Soberano del Tolima, "Cuentas del Estado Soberano del Tolima”, Gaceta del Tolima 34, 1877b, pp. 1-2.

78. Secretaría de Hacienda del Estado Soberano del Tolima. "Cuentas del Estado Soberano del Tolima”, Gaceta del Tolima 35, 1877c, pp. 1-2.

79. Secretaría de Hacienda del Estado Soberano del Tolima. "Cuentas del Estado Soberano del Tolima”, Gaceta del Tolima 36, 1877d, p. 1.

80. Sicard, M. Informe del Secretario de Hacienda al ciudadano Presidente del Estado Soberano del Tolima, Neiva, Imprenta del Departamento, 1886.

81. TePaske, J. J.; J. J. Hernández P. y M. L. Hernández P. La Real Hacienda de Nueva España: la Real Caja de México (1576-1816), México DF, Instituto Nacional de Antropología e Historia, Departamento de Investigaciones Históricas, 1976.

82. Tepaske, J.; H. Klein y K. Brown. The royal treasuries of Spanish empire in America, vol. 1, "Peru", Durham, Duke University Press, 1982a.

83. Tepaske, J.; H. Klein y K. Brown. The royal treasuries of Spanish empire in America, vol. 2, "Upper Peru", Durham, Duke University Press, 1982b.

84. Tepaske, J.; H. Klein y K. Brown. The royal treasuries of Spanish empire in America, vol. 3, "Chile y el Río de la Plata", Durham, Duke University Press, 1982c.

85. Torres S., R. El precio de la guerra. El Estado fiscal-militar de Carlos iii, 1779-1783, Madrid, Marcial Pons, 2013.

86. Tovar, H. Convocatoria al poder del número. Censos y estadísticas de la Nueva Granada, 1750-1830, Bogotá, Archivo General de la Nación, 1994.

87. Tovar, H. Que nos tengan en cuenta: colonos, empresarios y aldeas: Colombia 1800-1900, Bogotá, Tercer Mundo, 1995.

88. Wong H., A. "Las finanzas públicas en el Estado Soberano de Bolívar, 1857-1886”, Historia y Pensamiento 3, 1999, pp. 1-9. 